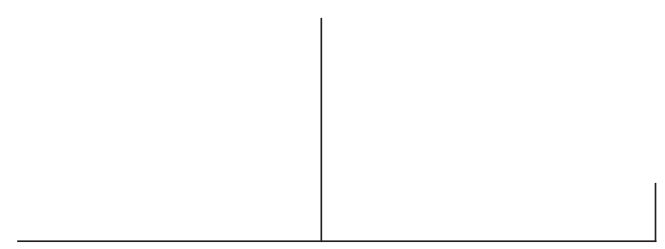

Rev. Latinoam. Psicopat. Fund., II, 2, 37-51

\title{
Convergências e divergências nas teorias do narcisismo de Kohut e de Lacan ${ }^{1}$
}

\author{
Luciana Gageiro Coutinho
}

\begin{abstract}
Kohut e Lacan construíram teorias bastante críticas em relação à teoria do ego autônomo de Hartmann, caracterizadas justamente por partirem de questões referentes ao narcisismo enfatizado no que diz respeito à sua estreita relação com o registro objetal. No entanto, as teorias de Kohut e de Lacan baseiam-se em certos princípios teóricos e clínicos divergentes.
\end{abstract}

Palavras-chave: Narcisismo, Kohut, Lacan, metapsicologia

1. Este artigo é proveniente de minha dissertação de mestrado, orientada pelo Prof. Dr. Octavio Souza, e defendida em agosto de 1997 no Depto. de Psicologia da PUC-RJ. 


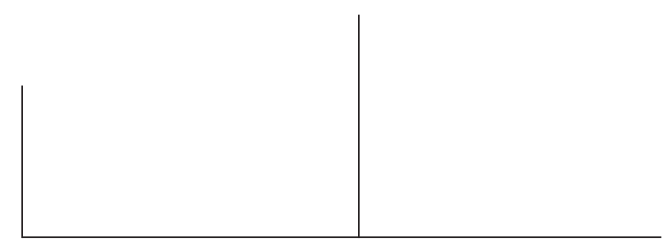

O campo da psicanálise é marcado por uma diversidade de posicionamentos teóricos, advindos da complexidade conceitual freudiana, que aponta, ao mesmo tempo, caminhos diversos ou até mesmo antagônicos. Dessa forma, o diálogo entre as diferentes escolas psicanalíticas desenvolvidas depois de Freud torna-se por vezes extremamente difícil, configurando uma verdadeira "Torre de Babel". Nossa proposta, porém, é tentar avançar diante destes embates teóricos, no sentido de construir uma reflexão acerca das produções de Kohut e Lacan sobre o narcisismo, construídas a partir do referencial freudiano.

Os conceitos elaborados por Freud apresentam-se ao longo de sua obra atrelados a diversas funções e desdobramentos, seja em diferentes momentos da construção de sua teoria, ou mesmo dentro de um único artigo. No caso do narcisismo, Freud começa a esboçar o conceito a partir das análises do homossexualismo e das chamadas "neuroses narcísicas", que lhe permitem chegar à concepção de que o ego é um objeto de amor, sendo investido libidinalmente da mesma maneira que outros objetos o são. Entretanto, o narcisismo só é apresentado mais detalhadamente como um conceito propriamente dito no artigo de 1914 "Sobre o narcisismo - uma introdução". Um dos aspectos que confere importância a este artigo é sua posição intermediária entre a primeira e a segunda tópica. Por isso mesmo, as considerações de Freud a respeito do narcisismo muitas vezes causam problemas, dando margem a diversas interpretações e tornando difícil a integração do conceito a outros princípios metapsicológicos e clínicos também formulados por Freud.

Apesar de se situarem em posições epistemológicas e institucionais muito diversas ${ }^{2}$, Kohut e Lacan possuem um aspecto

2. Enquanto Lacan emerge a partir de uma forte tradição psiquiátrica e filosófica francesa onde se destacavam a fenomenologia, o hegelianismo, o marxismo, e, mais tarde, o estruturalismo - Kohut alia o positivismo imperante nos EUA ao referencial empirista inglês, ancorando-se principalmente na psicologia do ego americana e na teoria das relações objetais de Melanie Klein. 


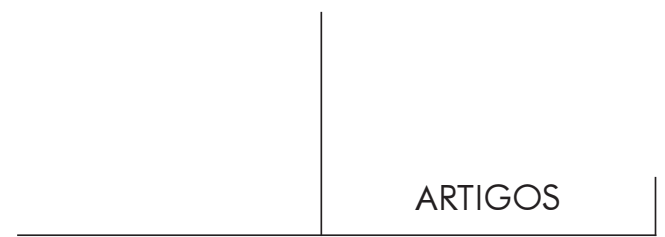

em comum em suas inspirações teóricas: o fato de que ambos se preocupam em travar um diálogo (crítico) com os teóricos da psicologia do ego. De alguma forma, tanto Kohut quanto Lacan procuram ultrapassar, em suas elaborações teóricas do narcisismo, o que julgavam insuficiente na psicologia do ego para dar conta das questões suscitadas pela clínica. Dito isto, propomo-nos a fazer um contraste entre as teorias de Kohut e de Lacan a respeito do narcisismo, tendo como pano de fundo a discussão de algumas categorias da psicologia do ego e daquilo que foi privilegiado por cada um para além da matriz freudiana. Investigaremos também de que forma estas novas construções teóricas repercutem na atividade clínica tal como foi abordada por cada um.

\section{O narcisismo na psicologia do ego}

Na psicologia do ego o narcisismo não é um conceito privilegiado. Os teóricos desta corrente, dentre os quais se destacam Hartmann, Kris e Lowenstein, discordam da equivalência feita entre narcisismo e investimento libidinal no ego. Referem-se à dificuldade de situar o conceito de narcisismo na teoria da segunda tópica de Freud, já que o ego passa a ser descrito como uma das três instâncias do aparelho psíquico. Hartmann (1939/1958) retoma, então, algumas passagens do texto sobre o narcisismo, em que Freud reporta-se claramente ao investimento na própria pessoa, no corpo, em si mesmo (self). Assim observa a importância de que se faça uma distinção entre os investimentos no ego - os quais se contrapõem a investimentos nas outras instâncias - e os investimentos no self - na própria "pessoa” em contraposição aos investimentos objetais.

Portanto, conforme afirma Hartmann (1950/1964), o narcisismo corresponde ao investimento libidinal do self, representação de si próprio, e não da instância egóica. Hartmann adota o termo self principalmente para designar a representação da própria pessoa, que, assim como as representações de objeto, pode se situar no ego, no superego ou no id. Em outras palavras, o conceito de self, que será tomado como base para a obra de Kohut, marca a oposição entre o investimento libidinal em si próprio e o investimento nos objetos.

A necessidade de diferenciação entre self e ego na psicologia do ego decorre do fato de que o pressuposto básico sobre o qual esta concepção teórica se funda é o conceito de "ego autônomo". A hipótese do "ego autônomo" pressupõe uma "área livre de conflitos" no ego, ou seja, que não está submetida às pulsões do id.

Nem toda adaptação ao meio ambiente, nem todo processo de aprendizagem ou maturação, é um conflito. Eu me refiro ao desenvolvimento, fora de conflito, da percepção, intenção, compreensão objetiva, pensamento, linguagem, fenômenos de memória, produtividade, às bem conhecidas fases do desenvolvimento motor, 
capacidade de agarrar com as mãos, engatinhar, andar e aos processos de maturação e aprendizagem implícitos em todos esses e muitos outros... Eu proponho que adotemos o termo provisório área do ego livre de conflitos para este conjunto de funções que, a qualquer dado momento, exercem seus efeitos fora da região mental de conflitos. (Heinz Hartmann, 1939/1958: 8, tradução minha)

Segundo Hartmann (1950/1964), há uma autonomia primária do ego que corresponde às funções inatas do organismo, tais como o controle da percepção e da motilidade, e uma autonomia secundária do ego, proveniente da neutralização das pulsões advindas do id. O modo pelo qual o ego alcança a autonomia secundária é principalmente através de uma neutralização das pulsões sexuais e agressivas. Sendo assim, o ego autônomo desenvolve-se através de sua capacidade de operar suas funções utilizando-se de uma libido dessexualizada (Hartmann, 1950/1964).

Na psicologia do ego, o conflito é concebido como um conflito entre as áreas de autonomia do ego e as áreas defensivas que estão subordinadas às pulsões e estão a serviço da resistência. O desenvolvimento do ego é descrito a partir dos conflitos que ele pôde solucionar com o id, o superego e o mundo externo, de modo que se estabelece no psiquismo uma divisão entre as áreas de conflito e as áreas pacíficas do ego. Nesta abordagem, a afirmativa freudiana clássica "Onde estava o id, ali estará o ego" (Freud, 1932-33/1976:102) é interpretada em termos de "onde houver ego conflituoso, o ego autônomo deve adquirir controle progressivo" (Rudolph Lowenstein, 1971: 20 - tradução minha). Portanto, o objetivo da análise é alargar esta área livre de conflitos do ego, ou seja, aumentar o grau de autonomia egóica mediante um aumento da capacidade do ego para a neutralização das pulsões sexuais e agressivas que geram conflitos.

Entretanto, ocorre que, na tentativa de isolar o problema do narcisismo através da definição de self, os psicólogos do ego não o discutem mais profundamente, deixando-o permanecer como um ponto confuso na teoria. Retomemos a definição de ego autônomo. O ego autônomo é aquele capaz de neutralizar os investimentos sexuais e agressivos que interferem nas suas funções e relações com a realidade. Em algumas passagens, por exemplo, a possibilidade de neutralização destes investimentos é atribuída a um maior investimento libidinal do self.

Também quero mencionar, de passagem, o fato clínico estabelecido de que a capacidade do ego para a neutralização é em parte dependente de um maior grau de investimento pulsional no self. O grau de neutralização é outro ponto a ser considerado - além dos já mencionados anteriormente - se quisermos descrever adequadamente a transição de um estado "narcisista" do ego para o seu posterior funcionamento em sintonia com a realidade. (Heinz Hartmann, 1950/1964: 129, tradução minha) 


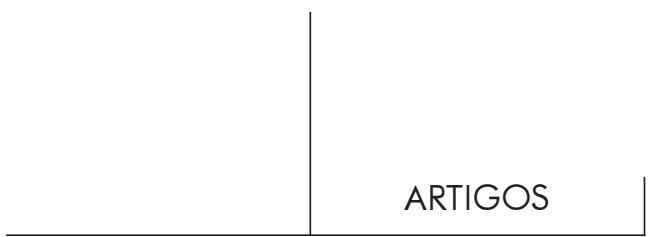

Nesse sentido, um self bem investido narcisicamente, manifestando-se por exemplo sob a forma de uma boa auto-estima, atuaria como facilitador para capacitar o ego a conquistar sua devida autonomia. Deveria haver, então, uma autonomia egóica, mas não uma autonomia do self? Isto não é satisfatoriamente explicado, permanecendo como um furo neste arcabouço teórico.

O que é patente na linha de pensamento proposta por Hartmann é que o aumento de autonomia do ego se dá através de uma transição de um estado de submissão pulsional do ego - "estado regressivo" - para um modo de funcionamento em sintonia com a realidade. O processo de neutralização da libido narcísica que, paradoxalmente, tal como foi exposto na citação acima, é proporcional ao grau de investimento narcísico na representação do self situada no ego em detrimento do investimento nos objetos reais, garante que a energia sexual do id possa ser direcionada pelo ego para objetos e finalidades adaptadas à realidade. Contudo, devemos notar que, à medida que a representação do self está localizada no interior do ego, há uma certa coerência no argumento de Hartmann ao considerar que mais libido do self pode representar, em sua forma neutralizada, mais energia disponível para o ego. Mas este processo não é descrito mais detalhadamente pelos teóricos desta vertente, permanecendo em suspenso uma compreensão mais aprofundada sobre a forma pela qual o narcisismo, entendido como o investimento libidinal do self, se integra ao restante de seu corpo teórico.

\section{Heinz Kohut e a psicologia do self}

A psicologia do self, concebida originalmente por Kohut, consiste, essencialmente, em uma teoria do narcisismo. Em "Formas e transformações do narcisismo", de 1966, Kohut enfoca o narcisismo como o próprio combustível da existência, aquilo que impulsiona e alimenta a vida psíquica. Nesse sentido, Kohut propõe uma teoria do narcisismo em que este não constitui apenas um estágio na constituição do psiquismo, mas sim um estado que permanece atuante e em progressivas transformações no funcionamento psíquico, seja em formas

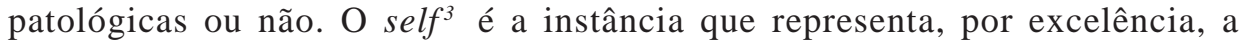
organização narcísica da subjetividade, desde os primórdios até a vida adulta.

O ego, o id e o superego são os componentes na psicanálise de uma abstração específica, de alto nível, isto é, distante da experiência: o aparelho psíquico (...). O

3. Este conceito é desenvolvido por Kohut a partir da formulação inicial feita por Hartmann, conforme descrevemos anteriormente. 


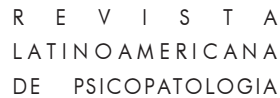

self, entretanto, surge na situação psicanalítica e é conceituado na forma de uma abstração de um nível relativamente baixo, isto é, relativamente próxima à experiência, como um conteúdo do aparelho mental. Embora não seja, dessa forma, uma instância da mente, é uma estrutura dentro da mente, pois: a) está catexizado com energia instintiva e b) tem continuidade no tempo, isto é, é duradouro. (Heinz Kohut, 1971/1988: 14)

Como podemos notar na citação acima, a teoria de Kohut é caracterizada por uma preocupação em manter a maior proximidade possível da experiência clínica. É através da observação das "transferências narcísicas" que Kohut nomeia seus conceitos clínicos e metapsicológicos fundamentais. Em seu primeiro livro, A análise do self, de 1971, Kohut apresenta vastas descrições destas transferências, chegando à conclusão de que o narcisismo não é incompatível com as relações objetais. Este é o ponto crucial do qual parte para o desenvolvimento de sua teoria.

Muitas relações de objeto são utilizadas com fins narcisistas. Em volta do bebê e em volta de nós existem objetos que têm para nós suma importância, mas que servem a fins narcisistas. Quando o bebê começa, por exemplo, a adquirir alguma idéia de seu próprio valor, de sua própria coesão, de que ele é alguém, necessita que outras pessoas lhe confirmem essa idéia. (Heinz Kohut, 1962/1990: 47, tradução minha)

Kohut afirma não apenas que há relações de objeto que são pautadas pelo narcisismo, mas, principalmente, que essas relações são fundamentais para a própria constituição do psiquismo. A partir desta hipótese, Kohut chega ao conceito de self-objeto, que serve de pilar para a sustentação de suas construções teóricas. Os self-objetos são definidos como aqueles objetos que estão a serviço do self, instância narcísica, alimentando a sua preservação e coesão. Ao longo do desenvolvimento, segundo Kohut, o self assume duas modalidades básicas de relação com seus self-objetos fundamentais, freqüentemente encarnados nas figuras da mãe e do pai: o "self grandioso" e a "imago parental idealizada". Estes conceitos dizem respeito a duas formas nas quais a libido narcísica se apresenta ao longo do desenvolvimento, designando dois padrões de relação com os selfobjetos, ambos pautados no narcisismo.

O self grandioso remete à dimensão primordial das nossas ambições e desejos - que se configura basicamente na relação mãe-bebê - enquanto a imago parental idealizada está predominantemente relacionada ao controle das ambições e desejos, bem como à sua regulação mediante os nossos ideais - que se cristalizam no momento do Édipo. Segundo Kohut, o self grandioso ancora-se em uma fantasia de grandiosidade, que se manifesta inicialmente através do exibicionismo, sendo este fenômeno um modelo típico de relação objetal na qual a ênfase é centrada 


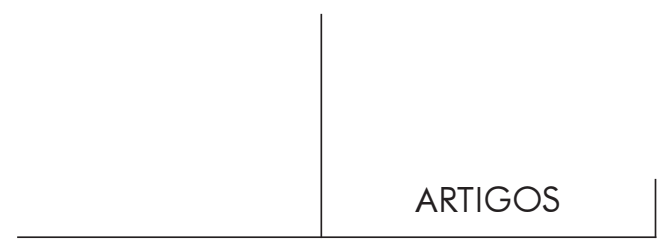

mais na finalidade da pulsão (no próprio self, como realizador) do que em seu objeto. O objeto é importante apenas enquanto convidado a participar do prazer narcísico da criança e assim confirmá-lo.

A fantasia de grandiosidade ocupa uma posição importante na estruturação da personalidade, exercendo a função de precursora da imago parental idealizada. Enquanto os impulsos narcísico-exibicionistas são considerados como o aspecto pulsional predominante do self grandioso, a fantasia grandiosa é o seu conteúdo ideacional. À medida que estes conteúdos ideacionais vão sendo cristalizados, torna-se possível o desenvolvimento do segundo pólo de transformação do narcisismo primário: a imago parental idealizada. Neste segundo momento de relação self-objetal, a ênfase recai sobre o objeto, percebido de forma idealizada. No entanto, para Kohut, esta idealização não tem um caráter negativo, mas sim participa como fator integrante para o amadurecimento do psiquismo, assim como para a consolidação das instâncias psíquicas.

Vale a pena acrescentar ainda que, na visão de Kohut, a meta analítica é descrita de forma semelhante à sua própria teoria da constituição do psiquismo, de forma que o narcisismo é bastante valorizado em suas diferentes manifestações. O objetivo não é a abolição da posição narcísica do paciente, mas sim uma transformação de seu narcisismo, isto é, trata-se de uma redistribuição da libido narcísica do paciente, assim como da integração de estruturas narcísicas primitivas à sua personalidade madura. Na perspectiva dele, mais explicitada nos seus últimos livros, A restauração do self (1977/1988) e Como cura a análise? (1981/1986), pode-se dizer que uma análise foi bem-sucedida quando se estabelece um self firme e coeso, resultante da internalização de determinadas funções self objetais, encarnadas pelo analista na transferência.

\section{Jacques Lacan e o estádio do espelho}

O conceito de narcisismo é trabalhado por Lacan no início de sua obra, nos termos de sua teoria do imaginário especular. No artigo sobre o estádio do espelho, de 1949, Lacan constrói a hipótese de que a representação do eu é possibilitada pela via de uma imagem integradora - a imagem especular. Retomando o experimento de Wallon sobre a criança e o reconhecimento de sua própria imagem no espelho, Lacan acentua o poder morfogênico dessa imagem, que não é um mero reflexo exterior passivo, mas geração do eu da criança. Ao

4. Utilizaremos aqui o termo eu, em vez de ego, já que Lacan também utilizava uma terminologia diversa da versão inglesa ("ego") para designar o eu ("je”-simbólico; "moi”-imaginário) em sua teoria. 


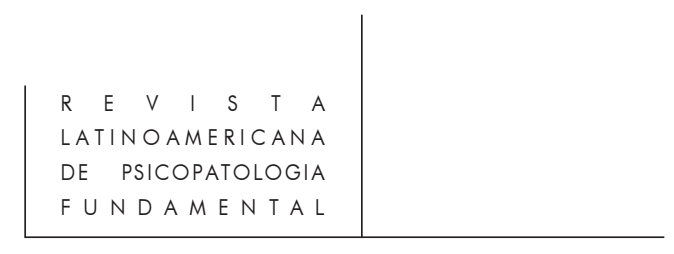

reconhecer-se na imagem, a criança tem uma representação de seu corpo unificado, distinta das sensações provenientes de sua motricidade, experimentadas de modo fragmentado. Desta forma, como observa Philippe Julien (1993), Lacan opera uma subversão da interpretação estabelecida: não há formação do eu através de sua exteriorização, de um movimento do interior para o exterior, por uma projeção. O que ocorre é o inverso: a constituição do eu depende de um movimento de identificação do sujeito com uma imagem especular que se configura ao seu redor.

No Seminário I - Os escritos técnicos de Freud, Lacan (1953-54/1979) retoma os postulados de "O estádio do espelho", introduzindo, porém, a função do registro do simbólico para a própria constituição do imaginário. Isto é feito principalmente através do uso de um esquema importado da física, conhecido como "esquema ótico". Utilizando-se desse esquema, Lacan menciona que a situação do sujeito é caracterizada, desde sempre, pela sua inserção no campo da linguagem. Com isto, acrescenta à teoria do estádio do espelho que é somente à medida que o sujeito tem um lugar no mundo simbólico - lugar que lhe é dado pelo Outro - que ele obtém a visão da imagem especular. No caso do bebê que se olha no espelho, pode-se dizer que o que Lacan acentua em 1953 é que alguém (possivelmente a mãe) deve mostrar ao bebê sua própria imagem, a partir de um lugar simbólico, para que ele possa de fato reconhecer-se nela. Em outras palavras, há um Outro (simbólico) que precede e determina permanentemente a configuração do eu. Para Lacan, a constituição da subjetividade se dá no interjogo entre o simbólico e o imaginário, sendo postulado um descentramento permanente do sujeito em relação ao eu (imagem à qual se tem acesso) ${ }^{5}$.

Através desse jogo entre virtualidade e realidade, Lacan define o eu como situado fora de nós, como uma imagem, como o outro que somos. Em outras palavras, segundo Lacan (1953-54/1979), dizer que o eu é imagem, é dizer que o eu é eu ideal, sendo formado a partir de uma determinação simbólica que o precede, o ideal do eu. O ideal do eu designa a ancoragem simbólica que permite a formação da imagem, situando-a em relação ao desejo do Outro. Portanto, é o ideal do eu que possibilita que toda dinâmica desejante do sujeito se instaure e se perpetue na articulação entre imaginário e simbólico.

Em outros termos, é a relação simbólica que define a posição do sujeito como aquele que vê. É a palavra, a função simbólica, que define o maior ou menor grau

5. Trabalhamos aqui apenas com os registros do imaginário e do simbólico, descritos no início da obra de Lacan, os quais consideramos suficientes para esta análise comparativa que nos propomos a fazer. Porém, não nos furtamos a admitir que, futuramente, a implementação do registro do real possibilitará uma redescrição deste interjogo entre alteridade e subjetividade a partir do conceito de objeto $a$. 


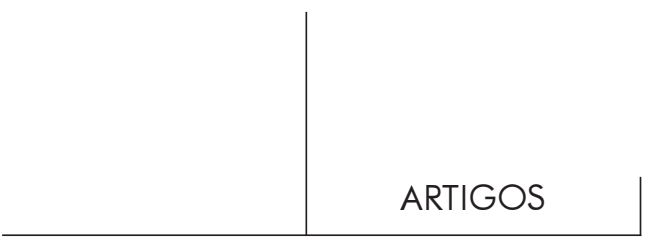

de perfeição, de completude, de aproximação do imaginário. A distinção é feita nessa representação entre o Ideal-ich e o Ich-ideal, entre o eu-ideal e o ideal do eu. O ideal do eu comanda o jogo das relações de que depende toda relação a outrem. E dessa relação a outrem depende o caráter mais ou menos satisfatório da estruturação imaginária. (Jacques Lacan, 1953-54/1979: 165)

Há uma relação permanente entre imaginário e simbólico, entre imagem e desejo. Lacan afirma que, imaginariamente, o desejo do sujeito está no desejo do outro. Mas é o simbólico (ideal do eu) que introduz a possibilidade de que o sujeito se reconheça como imagem (eu ideal) no outro, imagem na qual se aliena. Para que se possa sair dessa alienação, Lacan supõe a necessidade de um pacto, que é possibilitado pela fala. Sem a fala, o desejo só existe no plano da relação imaginária, ou seja, alienado no outro. Portanto, é com a fala que o sujeito é capaz de definir sua posição desejante singular. Partindo destes pressupostos, é no simbólico, mais especificamente na fala singular do sujeito, que Lacan deposita todo o interesse no início de sua obra, sendo também a ela atribuídos os ganhos terapêuticos obtidos numa análise.

Lacan afirma que a análise consiste, essencialmente, em um processo de reconhecimento do desejo no plano simbólico, mas que isto se dá a partir do reconhecimento dos investimentos imaginários. É o outro especular, que tem estreita relação com o eu, que o sujeito pode ver e tomar como objeto. A análise deve levar o sujeito a descobrir a que outros ele tem se dirigido ao longo de sua história. Uma das ferramentas básicas para este trabalho é a idéia de que, na análise, a identificação narcísica do sujeito à imagem, ou, ainda, os próprios investimentos imaginários, estão concentrados no plano da transferência. Porém, Lacan diz que, longe de ser um fenômeno apenas imaginário, a transferência é simbólica. Ao discernir e priorizar a dimensão simbólica da transferência, o que Lacan introduz é que "a transferência não é toda repetição, mas é a repetição de uma demanda dirigida do lugar do Outro, o retorno de uma demanda passada" (Philippe Julien, 1993: 63). Esta demanda volta, em formações do inconsciente e na transferência, porque não foi devidamente reconhecida pelo sujeito anteriormente. Desta forma, a repetição é compreendida como um apelo à nomeação. A especificidade da análise frente a outras relações nas quais a transferência pode se manifestar é exatamente o fato de que o analista a ela responde não do lugar do outro que diria "Tu és isso", mas sim do Outro, que reconhece justamente a nomeação simbólica feita pelo próprio sujeito. Portanto, na visão lacaniana, a transferência, porque é também simbólica, não é um obstáculo, não é mera repetição, mas é propiciadora de mudanças. 
$R \quad E \quad V \quad I \quad S \quad T \quad A$

LATINOAMERICANA

DE PSICOPATOLOGIA

F UNDAMENTAL

\section{Narcisismo: coincidências e divergências entre Lacan e Kohut}

Já de imediato, não é difícil perceber que tanto Kohut quanto Lacan se distanciam bastante da proposta da psicologia do ego, sendo esta distinção pautada principalmente pela questão do narcisismo. Em contraposição aos postulados da psicologia do ego, que enfatiza a autonomia egóica em relação às pulsões tomando o narcisismo como um investimento regressivo que deve ser superado para que os objetos da realidade possam ser investidos - pudemos perceber que tanto Kohut quanto Lacan concebem uma instância que é permanentemente investida libidinalmente: o self, para Kohut, o eu (moi), para Lacan. No entanto, até onde as abordagens de Lacan e Kohut se aproximam? Até que ponto as possíveis aproximações teóricas de seus postulados resultam em aproximações também em termos da proposta clínica veiculada por cada um?

Para efetuar este trabalho de contraste, o mapeamento do campo psicanalítico feito por Paul Bercherie (1984) no seu "O ocular quadrifocal" é bastante útil. A partir de alguns instrumentos de análise utilizados por Bercherie para mapear as diversas correntes da psicanálise, podemos perceber a presença de algumas categorias comuns na abordagem do narcisismo feitas pelas duas teorias. De acordo com Bercherie, ambos concebem o narcisismo como relacionado ao registro objetal. De modo análogo, ambos consideram que os fenômenos da idealização e da agressividade são manifestações do narcisismo no campo das relações objetais.

Em linhas gerais, Kohut e Lacan coincidem em abordar o narcisismo como um estado permanente ao qual está submetida a subjetividade. Da mesma maneira, ambos concebem o narcisismo necessariamente em relação ao registro objetal. Em contraposição aos postulados da teoria de Hartmann, Kohut abandona a preocupação com a adaptação do ego à realidade e constrói uma teoria das relações do self com seus objetos arcaicos (self-objetos), às quais atribui uma função privilegiada na constituição do psiquismo. No caso da teoria lacaniana, o próprio eu é um objeto, assim como o objeto é eu. A constituição narcísica do eu é simultânea à formação do objeto.

Em nosso entender, a semelhança entre Kohut e Lacan relativa ao registro objetal também se traduz por uma virada radical em relação à concepção de análise proposta pelos psicólogos do ego, sustentada em termos de uma aliança do analista com o ego do paciente, o qual, autonomamente, deveria desviar o investimento pulsional para objetos e objetivos mais favoráveis. Esta posição se sustenta na concepção do sujeito e do objeto (no caso, o paciente e o analista) como dois termos estanques de uma relação, o que condiciona uma proposta analítica de redução transferencial em prol de uma adequação da percepção à realidade dos 


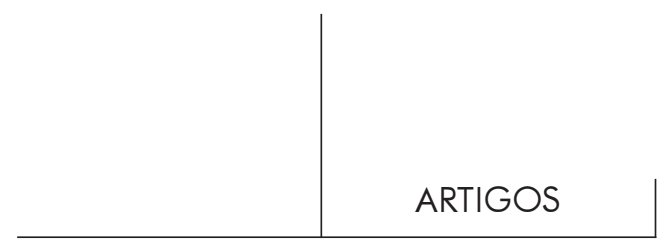

fatos. Por outro lado, tanto Kohut quanto Lacan vêem o trabalho de análise como um trabalho na transferência, onde a relação com o analista é o principal elemento representativo da subjetividade do paciente. Portanto, a subjetividade é concebida por ambos como estando, inevitavelmente, remetida ao registro objetal.

Entretanto, o que marca a diferença entre as concepções dos dois autores é o fato de que, na teoria lacaniana, o registro objetal se faz presente tanto através do registro do simbólico quanto do registro do imaginário. Como já vimos, o sujeito só pode se ver como um eu (moi), que corresponde a uma imagem especular de um outro - estando este ao nível do registro objetal imaginário. Porém, a grande novidade introduzida por Lacan é a sua teoria do simbólico, na qual a formação do eu como imagem depende inteiramente de um certo posicionamento simbólico, de um terceiro termo entre o sujeito e a imagem. A introdução do registro do simbólico representa, portanto, uma diferença crucial na abordagem lacaniana do narcisismo em relação à abordagem kohutiana. Para Lacan, o narcisismo pressupõe uma ancoragem simbólica, mas, imediatamente, também oblitera o acesso ao simbólico, e, logo, ao desejo inconsciente. A imagem é um engodo, uma ilusão, que se funda no desconhecimento dos determinantes simbólicos do desejo. Na teoria de Kohut, pelo contrário, o narcisismo é a via principal de acesso ao cerne da subjetividade, aquilo que impulsiona e direciona toda a dinâmica pulsional. Portanto, para Lacan, o narcisismo e a própria apreensão do eu como moi (imaginário) na análise, são resistências e devem ser atravessados, enquanto, para Kohut, é no terreno mesmo do narcisismo que a análise se dá, ou seja, há algo no próprio plano do narcisismo que é elaborado durante a análise.

As questões relativas à agressividade e à idealização também nos parecem ser pontos fundamentais na determinação de diferentes caminhos tomados por Kohut e Lacan em suas concepções de análise. Conforme mencionamos anteriormente, ambos apostam em um trabalho na transferência como criação, que promove novas saídas para determinados padrões de relação com os objetos, mas isto é feito a partir de referenciais bastante antagônicos.

Para Kohut, as mudanças subjetivas do paciente são concebidas em termos de desenvolvimentos, de reparações a determinadas falhas identificatórias, à medida que o analista se coloca como self-objeto empático, sendo a idealização um movimento propiciador do processo, enquanto, para Lacan, estas mudanças consistem justamente na saída de determinadas prisões identificatórias alienantes pela via simbólica da fala. Na concepção lacaniana, a idealização se enquadra como mais um exemplo de alienação imaginária do desejo no outro, desejo este que deve ser reapropriado pelo paciente ao ser falado em seu nome. Um dos níveis de leitura da assertiva "o desejo do homem é o desejo do outro" (Jacques Lacan, 1953-54/1979: 205) diz respeito, justamente, ao fato de que no plano imaginário 


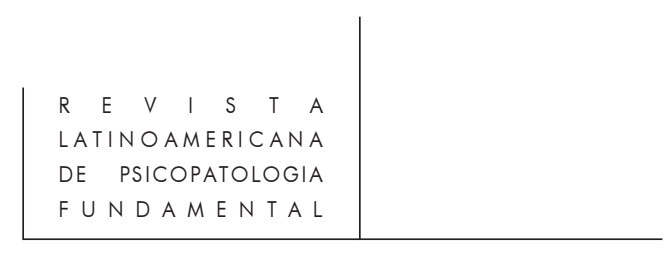

o sujeito está inteiramente capturado pelo outro. Nesta captura, o desejo do sujeito só pode exprimir-se nos termos imaginários do ódio e do amor, da rivalidade e da alienação passional. Isto explica porque, na visão lacaniana, a idealização não pode gerar mais do que puramente uma reação agressiva e deve ser superada na análise.

Kohut (1971/1984) também observa uma relação entre a agressividade e o narcisismo. Porém, a "fúria narcísica" é definida como uma reação do "indivíduo narcisicamente vulnerável" ao self-objeto que não satisfaz suas necessidades de suporte para o seu narcisismo, frustrando-o. Segundo o autor, isto é vivenciado como uma "ferida narcísica" que deve ser reparada na análise através da atuação do analista na transferência como um self-objeto empático, atento às necessidades narcísicas do paciente, que podem ser, por exemplo, de idealização.

Em resumo, parece-nos que, na proposta analítica de Kohut, a ênfase recai na experiência que o vínculo com o analista (possivelmente idealizado) proporciona ao paciente, resultando em uma maior coesão de seu self. Já na visão de Lacan, o laço com o analista idealizado é visto como imaginário, indo contra a proposição de que a relação analisando-analista deve se dar predominantemente em um eixo simbólico. Nesse sentido, o analista deve se situar como Outro (heterogêneo ao outro do narcisismo), de modo avesso à proposta de Kohut, visando justamente levar o analisando a sair de sua prisão imaginária.

Para finalizar, gostaríamos de abordar ainda uma coincidência interessante entre as teorias de Lacan e Kohut: o fato de que ambos abordam a experiência analítica como uma experiência trágica, fazendo um paralelo entre o percurso do herói da tragédia e a meta analítica. Em seu trabalho "Sobre a coragem", do início da década de 1970, Kohut faz esta analogia através da análise da história de alguns heróis-mártires que sacrificaram sua vida em nome de ideais. Segundo Kohut, a coragem destes personagens históricos deve-se a uma harmonização de todos os setores de suas personalidades em torno de seu self nuclear, ou seja, a uma integração das fantasias grandiosas e das idealizações arcaicas a suas personalidades adultas. Pois bem, neste raciocínio o homem trágico descrito por Kohut é aquele que tenta viver o padrão de seu self nuclear até as últimas consequiências, obtendo um "triunfo narcísico". Portanto, parece-nos que Kohut considera que a tragédia ilustra a forma pela qual o narcisismo intercede como motor da subjetividade, aquilo que, em sua visão, impulsiona a emergência da singularidade e o ímpeto de realizar o projeto de seu self nuclear.

Ao tocar no tema da tragédia, Lacan (1959-60/1988) também está falando da possibilidade da emergência da singularidade, no caso articulada à própria possibilidade da emergência do desejo. Antígona representa, neste sentido, uma história que retrata este processo de encontro do sujeito com o seu desejo, pressupondo um posicionamento singular em relação aos valores vigentes. Nesse 


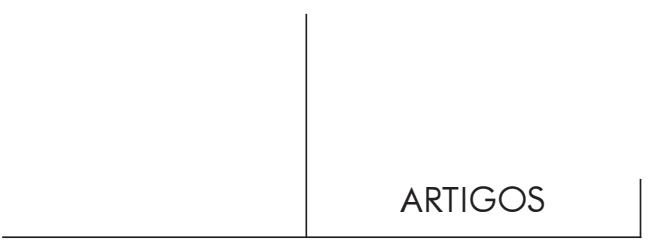

sentido, segundo Lacan, o mito trata do estabelecimento de uma relação trágica do sujeito com seus desejos, o que coincide a meta analítica no seu entender.

Enfim, consideramos que Kohut e Lacan são psicanalistas que vêem na tragédia, cada um a seu modo, uma via que leva a uma afirmação radical da singularidade, em detrimento de qualquer tentativa de uma adequação à realidade, tal como propunham os psicólogos do ego. Se avançarmos mais ainda, podemos perceber que ambos compartilham a idéia de que a meta analítica não implica meramente o abandono dos sintomas por parte do sujeito, mas, muito mais, a concepção de que o sujeito pode conservar seus sintomas e, ainda assim, estabelecer uma relação trágica com o seu desejo. Porém, enquanto para Kohut a via trágica é a via do narcisismo, para Lacan a dimensão trágica do humano diz respeito ao desejo. Ora, se em Kohut o narcisismo é aquilo que impulsiona o homem em sua existência, em Lacan é o desejo - e, necessariamente, a falta de objetos que possam satisfazê-lo plenamente - que ocupa este lugar.

\section{Considerações Finais}

Em nossa opinião, o argumento de Lacan contra o favorecimento da cristalização de determinados padrões identificatórios (imaginários) na análise é de fundamental importância. Por isso, Lacan valoriza muito mais a experiência simbólica do paciente do que a sua experiência imaginária, ligada à própria experiência afetiva do que está sendo falado para o analista, em sua teoria da clínica.

Entretanto, não consideramos menos importante valorizar a dimensão da experiência afetiva que o paciente tem com o seu analista e com os seus objetos de investimento privilegiados, no caso mais trabalhada por Kohut, no decorrer do processo analítico. Pensamos que é fundamental que esta dimensão afetiva da experiência esteja necessariamente presente (de forma falada ou atualizada na transferência) em toda análise, apesar de acatarmos o posicionamento de Lacan ao afirmar que a análise não se esgota aí. Uma boa análise transcende o plano imaginário, que é relativizado pelo simbólico, possibilitando o reconhecimento do desejo assim como um rearranjo dos investimentos e das identificações.

Deste modo, acreditamos que o diálogo entre as teorias de Lacan e de Kohut a respeito do narcisismo é bastante proveitoso para nos fazer pensar sobre as dimensões imaginária e simbólica da experiência analítica, bem como sobre o modo através do qual estas se apresentam em nossa clínica cotidiana. Enquanto Lacan demonstra estar sempre atento para os efeitos (imaginários) que uma "teoria da técnica" poderia dar margem - o que explica o uso freqüente de esquemas e metáforas como recursos para expor suas idéias - Kohut, por outro lado, não 


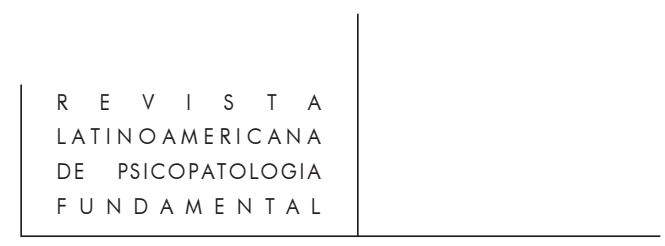

se preocupa com essa questão, o que pode ser notado, por exemplo, em seu modelo da relação analítica concebida como reedição da relação parental. Neste sentido, em uma linguagem lacaniana, talvez possamos afirmar que a teoria de Kohut nos convida a apreciar o papel fundamental da dimensão imaginária, representada pela própria imagem do eu e dos objetos, para que uma análise se torne viável.

\section{Bibliografia}

Bercherie, P. (1984). "L'oculaire quadrifocal (II) - epistémologie de l'héritage freudien: les quatre courants fondamentaux de la psychanalyse". Ornicar - Revue du Champ Freudien, 30. Paris, Navarin.

Coutinho, L.G. (1997). "Alguns destinos do conceito de narcisismo na teoria psicanalítica: um contraste entre as teorias da psicologia do ego, de Heinz Kohut e de Jacques Lacan". Dissertação de mestrado, PUC/RJ. Rio de Janeiro.

FreUd, S. (1914). "Sobre o narcisismo: uma introdução". ESB, vol. XIV. Rio de Janeiro, Imago, 1974.

(1932). "A dissecção da personalidade psíquica - Novas conferências introdutórias sobre psicanálise”. ESB, vol. XXII. Rio de Janeiro, Imago, 1976.

Hartmann, H. (1939). Ego Psychology and the Problems of Adaptation. New York, International Universities Press, 1958.

(1950). "Comments on the psychoanalytic theory of the ego", in Essays on the Ego Psychologie. New York, International Universitities Press, 1964.

Julien, P. (1993). O retorno a Freud de Jacques Lacan - aplicação ao espelho. Porto Alegre, Artes Médicas.

Koнuт, H. (1962). "Las lineas de desarrolo separadas del narcisismo y del amor objetal", in Elson, M. (org.). Los seminários de Heinz Kohut. Buenos Aires, Paidós, 1990.

(1966). "Formas e transformações do narcisismo", in Ornstein, P. (org.). Selfe narcisimo. Rio de Janeiro, Zahar, 1994.

(1988). "Sobre a coragem", in Stroizer, C. (org.). Psicologia do self e a cultura humana - Reflexões sobre uma nova abordagem psicanalítica. Porto Alegre, Artes Médicas.

(1971). "Reflexões acerca do narcisismo e da fúria narcísica", in Ornstein, P. (org.). Self e narcisimo, op. cit.

(1971). A análise do self . Rio de Janeiro, Imago, 1988.

(1977). A restauração do self. Rio de Janeiro, Imago, 1988.

(1981). Como cura el analisis? Buenos Aires, Paidós, 1986.

(1981). "Sobre a empatia". Conferência traduzida e apresentada na Jornada Brasileira de Psicologia do Self. Rio de Janeiro, Sociedade Brasileira de Psicanálise do Rio de Janeiro, 1992. 


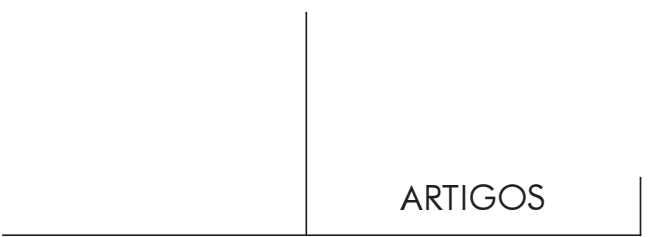

LACAN, J. (1949). "El estadio del espejo como formador del yo (je) tal como se nos revela en la experiência psicoanalítica", in Escritos 1. México, Siglo Veintiuno, 1994. Utilizamos uma tradução do texto original para o português feita por Luciano Elia (mimeo).

(1953-54). O Seminário - Livro 1 - Os escritos técnicos de Freud. Rio de Janeiro, Zahar, 1979.

(1959-60). O Seminário - Livro 7 - A ética da psicanálise. Rio de Janeiro, Zahar, 1988.

Lowenstein, R. (1971). "Ego autonomy and psychoanalitic technique", in The Psychoanalytic Study of the Child, 12. New York: International Universities Press.

\section{Resumos}

Kohut y Lacan construíron teorías bastante criticas con respecto a la teoría do ego autónomo de Hartmann, caracterizadas exactamente por partíren de cuestiones referentes al narcisismo enfatizado con respecto a su estrecha relación con el registro objectal. Mientras, las teorias de Kohut y de Lacan se basan en ciertos principios teóricos y clínicos divergentes.

Palabras-llave: Narcisismo, Kohut, Lacan, metapsicología.

Kohut et Lacan ont construit des théories assez critiques à l'égard de la théorie de l'ego autonome de Hartmann, caractérisées justement par le fait d'être issues de questions relatives au narcissisme, lequel est mis en relief dans ce qui touche à l'étroite relation avec le registre objectal. Néanmoins, les théories de Kohut et de Lacan se sont basées sur quelques principes théoriques et cliniques divergents.

Mots-clef: Narcisisme, Kohut, Lacan, metapsychologie.

Kohut and Lacan have built rather critical theories in relation to autonomous ego theory by Hartmann, characterized for deriving exactly from the questions referring to narcisism, that is enphasized in what concerns to its strict relationship with the objectal register. However, Kohut's and Lacan's theories are based on diverging clinical and theoretical principles.

Key words: Narcisism, Kohut, Lacan, metapsychology. 